\title{
The two extinctions of the Carolina parakeet
}

Kevin R. Burgio ${ }^{1,2 *}$, Colin J. Carlson ${ }^{3}$, Alexander L. Bond ${ }^{4}$, Margaret A. Rubega ${ }^{1}$, and Morgan W. Tingley ${ }^{1}$

${ }^{1}$ Department of Ecology and Evolutionary Biology, University of Connecticut, 75 N. Eagleville Rd, Storrs, CT, 06269 USA

${ }^{2}$ Education Department, Cary Institute of Ecosystem Studies, Millbrook, NY, USA

${ }^{3}$ Department of Biology, Georgetown University, Washington, D.C., USA. ORCID: 0000-00016960-8434

${ }^{4}$ Bird Group, Department of Life Sciences, The Natural History Museum, Akeman Street, Tring, Hertfordshire, HP23 6AP, UK. ORCID: 0000-0003-2125-7238

\section{Corresponding Author:}

* Kevin R. Burgio kevin.burgio@ gmail.com, ORCID: 0000-0002-8375-2501

2801 Sharon Turnpike, Millbrook, NY 12545

\section{Keywords:}

Extinction, Carolina Parakeet, Conuropsis carolinensis, extinction date estimation 


\section{ABSTRACT}

2 Due to climate change and habitat conversion, estimates of the number of species extinctions

3 over the next century are alarming. Coming up with solutions for conservation will require many

4 different approaches, including exploring the extinction processes of recently extinct species.

5 Given that parrots are the most threatened group of birds, information regarding parrot extinction

6 is especially pressing. While most recent parrot extinctions have been island endemics, the

7 Carolina parakeet (Conuropsis carolinensis) had an 18th-century range covering nearly half of

8 the present-day United States, despite which, they went extinct in the 20th century. The major

9 cause of their extinction remains unknown. As a first step to determining what caused their

10 extinction, we used a newly published, extensive dataset of Carolina parakeet observations

11 combined with a Bayesian extinction estimating model to determine the most likely date of their

12 extinction. By considering each of the two subspecies independently, we found that they went

13 extinct $\sim 30$ years apart: the western subspecies (C. c. ludovicianus) around 1914 and the eastern

14 subspecies (C. c. carolinensis) either in the late 1930s or mid-1940s. Had we only considered all

15 observations together, this pattern would have been obscured, missing a major clue to the

16 Carolina parakeet's extinction. Since the Carolina parakeet was a wide-ranging species that went

17 extinct during a period of rapid agricultural and industrial expansion, conditions that mirror those

18 presently occurring in many parts of the world where parrot diversity is highest, any lessons we

19 can glean from their disappearance may be vital to modern parrot conservation efforts. 


\section{INTRODUCTION}

25 We are entering the early stages of the "Sixth Mass Extinction" (Ceballos et al. 2015), where

26 estimates of the proportion of species to go extinct over the next century are dire (e.g., Urban

27 2015, Carlson et al. 2017) and species may not be able to adapt quickly enough to respond to

28 climate change (Keogan et al. 2018, Radchuk et al. 2019). This amount of loss will destabilize

29 already compromised ecosystems, while conservation agencies are finding it difficult to plan for

30 the challenges and uncertainty ahead (Armsworth et al. 2015). While our best guesses about how

31 and when species will go extinct in the future are largely based on model predictions, much can

32 be gained by studying the spatial, temporal, and mechanistic processes that led to recent

33 extinctions (e.g., Stanton 2014, Bond et al. 2019). Investigating the past may not only allow us to

34 recover some of the natural history lost with the extinction of these species but may also yield

35 important insights that can inform conservation actions now and in the future.

Parrots are one of the most threatened orders of birds, with $\sim 43 \%$ of all species listed as

37 near-threatened or worse by the IUCN (Marsden \& Royle 2015), and they face many different

38 pressures, including habitat loss and trapping (Snyder et al. 2000). Parrots are "keystone

39 mutualists," providing many important ecosystem functions (Tella et al. 2015, Blanco et al.

40 2016). The loss of parrots would affect plant species especially, contributing to ecosystem

41 instability. While a handful of parrot species have gone extinct over the past few centuries, most

42 were endemic to islands (Olah et al. 2016). There is, however, one notable exception - the

43 Carolina parakeet (Conuropsis carolinensis), which had a geographic range an order of

44 magnitude larger than the average for all other recently extinct parrot species (Olah et al. 2016).

45 Even though Carolina parakeets were charismatic and were of considerable interest to 
46 ornithologists during the 1800s, we know little about their biology or how and when they went

47 extinct.

The Carolina parakeet is one of the four forest-dependent bird species to go extinct within

49 the continental United States since the arrival of Europeans (Pimm \& Askins 1995). Before its

50 decline, the Carolina parakeet was widely distributed, with a range stretching from the mid-

51 Atlantic coast to Nebraska, and south to Florida (Burgio et al. 2017). The Carolina parakeet has

52 two subspecies (C. c. ludovicianus and C. c. carolinensis) but was not studied in detail while

53 extant. Thus, much of the information regarding their natural history is speculative. Accounts of

54 the species show a gradual population decline starting with European colonization (Snyder and

55 Russell 2002). By the early 1800s, Audubon (1831) noted a marked decline in their population

56 numbers and range, although he still considered them relatively common. During their decline,

57 the species' range receded from east to west toward the Mississippi River (except in Florida),

58 and from north to south, along the Ohio River, seemingly in concert with the expansion of

59 European expansion, destruction of bottomland forests, and the rise of intensive agriculture

60 (Askins 2000).

It is unclear exactly why the Carolina parakeet went extinct. People shot Carolina parakeets for sport, food, feathers, scientific collections, and to protect crops (Snyder and Russell

63 2002). However, it seems unlikely that overexploitation was a major contributor to their

64 extinction (McKinley 1980, Snyder 2004). Others have suggested other potential causes, such as

65 competition for food with other avian species, habitat loss, competition with introduced

66 European honey bees (Apis mellifera) over nesting/roosting sites, disease, and pressure from

67 trapping for the pet trade (McKinley 1980, Brunswig et al. 1983, Pimm and Askins 1995, Snyder

68 \& Russell 2002). 
Additionally, it is also unclear when the Carolina parakeet went extinct. At the turn of the

70 twentieth century, the Carolina parakeet could be found only in Florida, South Carolina, and a

71 few isolated regions west of the Mississippi River (Hasbrouck 1891, Snyder 2004). The last

72 captive Carolina parakeet died in a zoo about 100 years ago in 1918. The last "accepted" sighting

73 of the parakeet occurred in Florida in 1920 (Snyder 2004), but there were reports of the Carolina

74 parakeet into the 1930s and 1940s in both Florida and the Carolinas (Snyder 2004) which were

75 likely legitimate (Wright 2005). Determining exactly when the Carolina parakeet went extinct is

76 the first step in unraveling the mystery of how they went extinct, a question that may help

77 provide valuable information for parrot conservation and for any future "de-extinction" efforts,

78 for which they are considered a good candidate (Seddon et al. 2014). Here, we use a newly

79 published, extensive dataset of Carolina parakeet occurrence (Burgio et al. 2018), paired with

80 recent advances in extinction date estimation (Solow and Beet 2014, Kodikara et al. 2018), to

81 determine when these iconic parakeets went extinct.

\section{METHODS}

\section{Data collection}

84 We collected and georeferenced locality data from Carolina parakeet specimens found in natural

85 history collections around the world and observations of Carolina parakeets published in the

86 literature from 1564 to 1944 (see Burgio et al. [2018] for the description of the data collection

87 methods and a link to the freely available dataset). We then split our dataset by subspecies. We

88 considered all occurrence points west of the Appalachian crest and west of Alabama to be C. $c$.

89 ludovicianus and points east of the Appalachian crest and east of the state of Mississippi to be $C$.

90 c. carolinensis. These broad geographic delineations are generally accepted as the range limits of 
91 the two subspecies (Ridgway 1916, Swenk 1934), and are consistent with the subspecies

92 identifications listed on all 261 labeled museum specimens represented in the dataset for which

93 subspecies was recorded or inferred.

94 We determined the level of certainty of each observation based on expert opinion from

95 the literature, from Snyder (2004) and 18 articles by McKinley (1960, 1964, 1965,1976, 1977a,

96 1977b, 1978a, 1978b, 1978c, 1978d, 1979a, 1979b, 1979c, 1979d, 1981, 1985, McKinley \&

97 James 1984, McKinley \& Hardy 1985). We truncated our analysis at 1800, as observations

98 before 1800 were sporadic due, primarily, to a lack of consistent occurrence records and also

99 because this was the point at which Audubon (1831) noted decreasing numbers of Carolina

100 parakeets. Within this framework, we used the entire dataset and designated physical evidence,

101 such as a specimen, as "1", while observations considered legitimate by expert opinion, but not

102 interrogable in the present as " 2 ", and controversial as " 3 ." When individual years had multiple

103 records, we always used the evidence with the highest certainty (Figure 1a, 1b). While the last

104 "official" sighting of the Carolina Parakeet was in 1920 (Synder 2004), contemporary experts

105 consider the sightings in the Santee swamp area in South Carolina the 1930s to be legitimate

106 (Snyder 2004, Wright 2005), therefore we treated all reported sightings after 1920 as

107 unconfirmed, aside from those sightings in South Carolina.

\section{Analyses}

109 We estimated the date of extinction for all Carolina parakeets generally and both subspecies

110 specifically. Given that our dataset combined physical evidence (i.e., specimens) and

111 observations with varying degrees of reliability, we used the Bayesian extinction estimating

112 equations proposed by Solow et al. (2012) and modified by Solow and Beet (2014). We ran the 
113 analyses in the R package "spatExtinct" (Carlson et al. 2018a). This modeling approach weighs

114 various types of evidence based on their reliability (Solow et al. 2012), and considers the validity

115 of certain and uncertain sightings independently (Boakes et al. 2015, Kodikara et al. 2018),

116 which is especially useful in inferring extinction dates $\left(\tau_{\mathrm{E}}\right)$ of recently extinct species with both

117 specimen and observation data (Carlson et al. 2018b, Bond et al. 2019). Of the two models

118 presented in Solow and Beet (2014), we used "Model 2" because some of "uncertain"

119 observations are from reportedly dubious sources (e.g. egg hunters with a vested interest in

120 selling more expensive Carolina parakeet eggs) and "Model 2" is appropriate when uncertain

121 sightings are more likely invalid (Kodikara et al. 2018). We ran these analyses independently for

122 each subspecies (C. c. carolinensis: $\mathrm{n}=76 ;$ C. c. ludovicianus: $\mathrm{n}=80$ ), and both subspecies

123 together $(\mathrm{n}=116)$.

\section{RESULTS}

125 We estimated that the eastern subspecies, C. c. carolinensis, likely went extinct somewhere in

126 the late 1930s or the mid-1940s, with the two most likely values for $\tau_{\mathrm{E}}$ in 1938 and 1944 (Fig.

127 1c) while the western subspecies, C. c. ludovicianus went extinct 25-30 years earlier; the most

128 likely value for $\tau_{\mathrm{E}}$ was 1913 (Fig. 1c). When considering both subspecies together, the extinction

129 estimate doesn't differ much from the estimate for C. c. carolinensis since the highest probability

130 of $\tau_{\mathrm{E}}$ was 1939 (Fig. 1c); however, failing to consider each subspecies individually obscures

131 important distinctions between the two, especially for inferring causation.

\section{DISCUSSION}

133 The two separate subspecies of the Carolina parakeet appeared to go extinct $\sim 30$ years apart, far

134 later than currently believed, beyond the currently accepted date of 1920 and the most recent 
135 analysis that estimated they went extinct around 1915 (Elphick et al. 2010). Elphick et al. (2010),

136 however, used a less complete dataset and did not take into account uncertain sightings. While

137 largely dismissed at the time (Snyder 2004), our results lend credibility to the sightings in South

138 Carolina in the late 1930s. It is even possible that the observation from North Carolina in 1944

139 reported to Roger Tory Peterson (Snyder 2004) may have been accurate, as well as the mystery

140 population of Carolina parakeets in Florida reported by ornithologist Oscar Baynard to persist

141 well into the late 1930s, but for which he refused to disclose the location (Snyder 2004). That the

142 western subspecies went extinct first despite occupying a larger range (Burgio et al. 2017) is

143 curious, and suggests a lower initial population, or different or more severe pressures.

144 The Carolina parakeet continues to be one of the most popular proposed targets for de-

145 extinction projects (Seddon et al. 2014). Aside from the ethical issues surrounding de-extinction

146 generally (see Blockstein 2017), unless researchers can identify the major driver of their

147 extinction, de-extinction efforts for the Carolina parakeet may be doomed to fail at great expense

148 in both time and money. Despite a lack of evidence, many believe that farmers, egg poachers,

149 and trappers pushed the species to extinction (McKinley 1980, Snyder 2004), buoyed in part by

150 the lurid anecdote of a farmer shooting the parakeets in his orchard found in Audubon's

151 foundational book on North American birds (Audubon 1831). While the evidence is indeed

152 scant, researchers who have focused on this species over the past $60+$ years point to a disease

153 likely transmitted from domestic poultry as the most likely cause but have not settled on which

154 disease (McKinley 1980, Snyder and Russell 2002). Finally, the landscape across the parakeet's

155 former range has shifted dramatically since their decline started around 1800, which would make

156 de-extinction efforts difficult at best, especially when considering the uncertainty associated with

157 climate change. 
159 is the first of many steps needed to solve the mystery that has eluded researchers for well over 50

160 years. That the two subspecies went extinct 30 years apart is an important clue which has

161 implications for how we interpret the loss of this species and consider the factors that pushed a

162 species that appeared stable in 1800 to be found only in small populations in remote areas 100

163 years later. The limitations in both landscape change data and occurrence data may make it

164 difficult to rule out habitat loss as a major factor (but see Pimm and Askins 1995). Advances in

165 genetic analyses, as seen recently seen with passenger pigeons (Ectopistes migratorius; Hung et

166 al. 2015), or examining the few preserved specimens in natural history museums for signs of

167 disease (e.g., Rothschild \& Panza 2005) may help shed light on what ultimately drove the

168 Carolina parakeet to extinction. The Carolina parakeet was a wide-ranging species and faced

169 challenges of the rapid agricultural expansion and industrialization of the United States during

170 the 20th century, a process being repeated today in many areas where parrots are found. Given

171 that parrots are so threatened, determining the cause of the Carolina parakeet extinction is

172 especially pressing.

173

174 ACKNOWLEDGMENTS

175 K. Burgio was supported by a National Science Foundation GRFP grant \# DGE-0753455 and a

176 National Science Foundation NRT-IGE grant \#1545458 to M. Rubega.

\section{REFERENCES}

179 Armsworth, P. R., Larson, E. R., Jackson, S. T., Sax, D. F., Simonin, P., Blossey, B., Green, N.,

Ecol Environ 13: 163-169. 
Askins, R. 2000. Restoring North America's birds: lessons from landscape ecology. Yale University Press.

Audubon, J.J. 1831. Ornithological biography. Volume 1. Adam and Charles Black.

Boakes, E. H., Rout, T. M. and Collen, B. 2015. Inferring species extinction: the use of sighting records. Meth Ecol \& Evol 6: 678-687.

Bond, A.L., Carlson, C.J. and Burgio, K.R. 2019. Local extinction of insular avifauna on the most remote inhabited island in the world. J Ornith 160: 49-60.

Blockstein, D.E. 2017. We Can't Bring Back the Passenger Pigeon: The Ethics of Deception Around De-extinction. Ethics, Policy, \& the Envir 20:33-37.

Brunswig, N. L., Winton, S. G. and Hamel, P. B. 1983. A dietary overlap of evening grosbeaks and Carolina parakeets. - Wilson Bull 95: 452.

Burgio, K.R., Carlson, C.J. and Tingley, M.W. 2017. Lazarus ecology: recovering the natural history of the extinct Carolina parakeet. Ecol \& Evol 7:5467-5475.

Burgio, K.R., Carlson, C.J. and Bond, A.L. 2018. Georeferenced sighting and specimen occurrence data of the extinct Carolina Parakeet 1564 - 1944. Biodiv Data J 6: e25280.

Carlson, C.J, Burgio, K.R., Dougherty, E.R., Phillips, A.J., Bueno, V.M., Clements, C.F., Castaldo, G., Dallas, T., Cizauskas, C.A., Cumming, G., Doña, J., Harris, N.C., Jovani, R., Mironov, S., Muellerklein, O., Proctor, H.C. and Getz, W.M. 2017. Parasite biodiversity faces extinction and redistribution in a changing climate. Sci Advances 3(9):

Carlson, C.J., Burgio, K.R., Dallas, T.A., and Bond, A.L. 2018a. Spatial extinction date

Carlson, C.J., Bond A.L. and Burgio, K.R. 2018b. Estimating the extinction date of the estimation: a novel method for reconstructing spatiotemporal patterns of extinction and identifying potential zones of rediscovery. bioRxiv:276879.

210 Ceballos, G., Ehrlich, P. R., Barnosky, A. D., García, A., Pringle, R. M. and Palmer, T. M. 2015.

213 Elphick, C. S., Roberts, D. L. and Reed, J. M. 2010. Estimated dates of recent extinctions for North American and Hawaiian birds. Biol Cons 143: 617-624.

215 Hasbrouck, E. M. 1891. The Carolina Paroquet (Conurus carolinensis). Auk 8: 369-379. 
Hung, C. M., Shaner, P. J., Zink, R. M., Liu, W. C., Chu, T. C., Huang, W. S. and Li, S. H. 2014. Drastic population fluctuations explain the rapid extinction of the passenger pigeon. Proc Natl Acad Sci USA 111: 10636-10641.

Keogan, K., Daunt, F., Wanless, S., Phillips, R.A., Walling, C.A., Agnew, P., Ainley, D.G., Anker-Nilssen, T., Ballard, G., Barrett, R.T. and Barton, K.J. 2018. Global phenological insensitivity to shifting ocean temperatures among seabirds. Nature Climate Change 8: 313.

Kodikara, S., Demirhan, H. and Stone L. 2018. Inferring about the extinction of a species using

Marsden, S. J., and Royle, K. 2015. Abundance and abundance change in the world's parrots. certain and uncertain sightings. J Theor Biol. 442: 98-109. Ibis 157: 219-229.

McKinley, D. 1960. The Carolina parakeet in pioneer Missouri. Wilson Bull 72: 274-287.

McKinley, D. 1964. History of the Carolina Parakeet in its Southwestern Range. Wilson Bull 76: 68-93.

McKinley, D. 1965. The Carolina Parakeet in the Upper Missouri and Mississippi river valleys. Auk 82: 215-226.

233 McKinley, D. 1977a. Records of the Carolina Parakeet in Ohio. Ohio J Sci 77:3.

234 McKinley, D. 1977b. The Carolina Parakeet in Georgia: a review of reports. Oriole 42:21-25.

235 McKinley, D. 1978a. The Carolina Parakeet in the Virginias: a review. Raven 49:3-10.

236 McKinley, D. 1978b. The Carolina Parakeet in Alabama, a History. EOS (Alabama Mus Nat Hist) 1:7.

McKinley, D. 1978c. The Carolina Parakeet in Illinois: a recapitulation. Indiana Audubon Q 56:53-68.

McKinley, D. 1978d. The Carolina parakeet in the west: additional references. Nebraska Bird Rev 46:3-7.

McKinley, D. 1979a. A Review of the Carolina Parakeet in Tennessee. Migrant 50:1-6.

McKinley, D. 1979b. Historical review of the Carolina parakeet in the Carolinas. Brimleyana.

McKinley, D. 1979c. History of the Carolina parakeet in Pennsylvania, New Jersey, Delaware,

247 McKinley, D. 1979d. The Carolina Parakeet in Kentucky. Indiana Audubon Q 57:187-195. 
McKinley, D. 1980. The balance of decimating factors and recruitment in extinction of the Carolina Parakeet. Part 1. Indiana Audubon Quarterly 58: 8-18.

McKinley, D. 1981. The Carolina Parakeet in Mississippi: A Historical Review. Mississippi Kite. 11:2-6.

McKinley, D. 1985. The Carolina Parakeet in New York and Ontario: A Review and a Footnote. Kingbird. 167-172.

254 McKinley, D. and J. W. Hardy. 1985. The Carolina Parakeet in Florida. Florida Ornith Soc.

255 McKinley, D. and D. James. 1984. A Summary Account of the Carolina Parakeet in Arkansas.

Olah, G., Butchart, S. H., Symes, A., Guzmán, I. M., Cunningham, R., Brightsmith, D. J. and Ark Acad Sci Proc 38:64-67.

Pimm, S.L. and Askins, R.A. 1995. Forest losses predict bird extinctions in eastern North Heinsohn, R. Ecological and socio-economic factors affecting extinction risk in parrots. Biodivers Conserv 25: 205-223.

Radchuk, V., Reed, T., Teplitsky, C., van de Pol, M., Charmantier, A., Hassall, C., Adamík, P., Adriaensen, F., Ahola, M.P., Arcese, P. and Avilés, J.M., 2019. Adaptive responses of animals to climate change are most likely insufficient. Nature Comm 10: 1-14.

Ridgway, R. 1916. The birds of North and Middle America, Vol. 50 \#7. U.S. Government Printing Office.

Rothschild, B. M. and Panza, R. K. 2005. Epidemiologic assessment of trauma-independent skeletal pathology in non-passerine birds from museum collections. Avian Pathol 34: 212-219.

Seddon, P.J., Moehrenschlager, A. and Ewen, J. 2014. Reintroducing resurrected species:

Snyder, N. F. 2004. The Carolina Parakeet: Glimpses of a vanished bird. - Princeton University Press.

Snyder, N. F. and Russell, K. 2002. Carolina Parakeet (Conuropsis carolinensis). - In: Poole, A.

Snyder, N. F. R., McGowan, P., Gilardi, J. and Grajal, A. 2000. Parrots: status survey and conservation action plan 2000-2004. IUCN.

278 Solow, A., Smith, W., Burgman, M., Rout, T., Wintle, B. and Roberts, D. 2012. Uncertain Sightings and the Extinction of the Ivory-Billed Woodpecker. Conserv Biol 26: 180-184. 
280 Solow, A. R. and Beet, A. R. 2014. On uncertain sightings and inference about extinction.

281 Conserv Biol 28: 1119-1123.

282 Stanton, J. C. 2014. Present-day risk assessment would have predicted the extinction of the 283 passenger pigeon (Ectopistes migratorius). Biol Conserv 180: 11-20.

284 Swenk, M. H. 1934. The interior Carolina paroquet as a Nebraska bird. Nebraska Bird Rev 2: 5528559.

286 Urban, M. C. 2015. Accelerating extinction risk from climate change. Science 348: 571-573.

287 Wilson, A. 1829. American Ornithology, Vol. 3. Bradsford and Inskeep. 

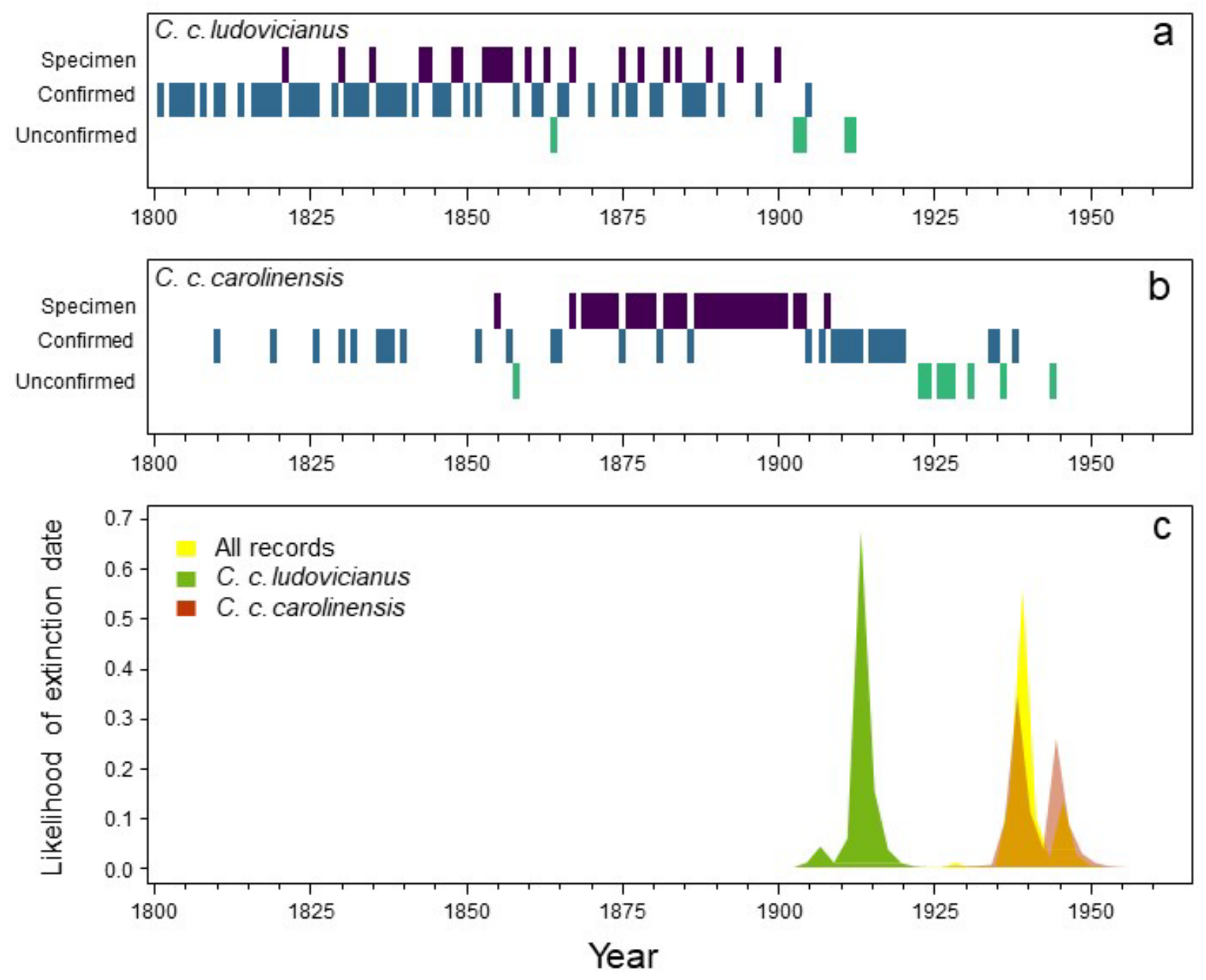

293 Figure 1. a. The sighting record for C. c. carolinensis. b. The sighting record for C. c.

294 ludovicianus. For panels a and b, the top row represents specimen records (purple), the middle

295 row represents confirmed observations (blue), and the bottom row represents unconfirmed or

296 controversial records (green). For each year, we used data with the highest certainty. c. The

297 estimates of likely extinction dates for C. c. ludovicianus (green), C. c. carolinensis (orange), and

298 for all records (yellow). 